\title{
Afirmação e produção de liberdade: desafio para os centros de atenção psicossocial ${ }^{*}$
}

\author{
The affirmation and production of freedom: a \\ challenge for the psychosocial care centers
}

\author{
Fernanda Nicácio ${ }^{1}$, Gastão Wagner de Sousa Campos ${ }^{2}$
}

\begin{abstract}
NICÁCIO, F., CAMPOS, G. W. de S. Afirmação e produção de liberdade: desafio para os centros de atenção psicossocial. Rev. Ter. Ocup. Univ. São Paulo, v.18, n. 3, p. 143-151, set./dez. 2007.

RESUMO: A análise do panorama da atenção em saúde mental no contexto do Sistema Único de Saúde indica um momento significativo do processo de mudança do modelo de atenção. Nesse cenário é fundamental aprofundar a reflexão sobre os desafios de tradução dos princípios e diretrizes da reforma psiquiátrica na prática dos serviços e projetos substitutivos e, especialmente, dos centros de atenção psicossocial, dispositivos estratégicos das redes de atenção psicossocial. Tomando como referência as contribuições basaglianas e de autores da desinstitucionalização, e a análise da trajetória do Núcleo de Atenção Psicossocial da Zona Noroeste como serviço aberto, territorial, 24 horas e substitutivo, partes integrantes do estudo desenvolvido, este artigo discute a centralidade da afirmação da liberdade para a superação do modelo asilar. Destaca que essa perspectiva imprime inovações na prática terapêutica, inscreve novas profissionalidades, e representa uma nova projetualidade nos processos de co-produzir com as pessoas com a experiência do sofrimento psíquico projetos de vida nos territórios.
\end{abstract}

PALAVRAS-CHAVE: Saúde mental. Desinstitucionalização. Serviços de saúde mental/tendências. Serviços comunitários de saúde mental. Terapia Ocupacional/tendências.

* O artigo apresenta parte integrante da tese "Utopia da realidade. Contribuições da desinstitucionalização para a invenção de serviços de saúde mental" defendida na Faculdade de Ciências Médicas da UNICAMP em 2003.

1. Doutora em Saúde Coletiva, Professora Doutora do Curso de Terapia Ocupacional do Departamento de Fisioterapia, Fonoaudiologia e Terapia Ocupacional da FMUSP.

2. Doutor em Saúde Coletiva, Professor Titular do Departamento de Medicina Preventiva e Social da Faculdade de Ciências Médicas da UNICAMP.

Endereço para correspondência: Departamento de Fisioterapia, Fonoaudiologia e Terapia Ocupacional da Faculdade de Medicina da Universidade de São Paulo. Rua Cipotânea, 51, Cidade Universitária, São Paulo, CEP 05360-160, e-mail: centroto@usp.br. 


\section{INTRODUÇ̃̃O}

"Saúde mental: cuidar em liberdade e promover a cidadania" (BRASIL, 2004). "Liberdade é o melhor cuidado" (BRASIL, 2001). "Liberdade ainda que Tam-Tam" (FMSM). "Saúde mental: poder, afeto, e liberdade” (KINOSHITA, 1989).

$\mathrm{E}$ ssas insígnias são alguns exemplos das diversas expressões produzidas na trajetória da reforma psiquiátrica que podem revelar a relevância da afirmação da liberdade para o processo em curso no cenário nacional. Afirmação indicativa de uma nova ética que, certamente transcende as fronteiras do específico, e, ao mesmo tempo, exige interações inovadoras com a experiência da loucura em diferentes dimensões. Se tomarmos o campo da atenção, a afirmação da liberdade imprime múltiplas possibilidades e também indagações: essa perspectiva refere-se aos processos de transformação e superação dos hospitais psiquiátricos e também à construção dos serviços substitutivos e territoriais? Quais significados inscreve nas práticas de cuidado no cotidiano das relações institucionais e, em particular, quais implicações para os profissionais?

A discussão dessas questões torna-se especialmente importante na atualidade considerando que a análise do panorama da atenção em saúde mental no contexto do Sistema Único de Saúde (SUS) indica um momento particularmente significativo do processo de mudança do modelo de atenção (BRASIL, 2007). Nesse cenário, é fundamental aprofundar a reflexão sobre os desafios de tradução das diretrizes, princípios, e projetualidade da reforma psiquiátrica na prática cotidiana dos serviços e projetos territoriais e substitutivos e, em particular, dos centros de atenção psicossocial (CAPS), dispositivos estratégicos das redes locais de atenção psicossocial.

Este artigo discute a centralidade da afirmação da liberdade para a superação do modelo asilar, apresentando parte integrante do estudo que descreveu e analisou, em diálogo com autores da desinstitucionalização e do campo da saúde coletiva, o Núcleo de Atenção Psicossocial (NAPS) da Zona Noroeste no contexto da experiência santista de saúde mental, durante o período de 1989 a 1996, identificando um conjunto de temáticas no processo de sua construção como serviço aberto, territorial, 24 horas e substitutivo, dentre as quais, a produção de liberdade (NICÁCIO, 2003). Para essa reflexão é fundamental revisitar as contribuições basaglianas e da desinstitucionalização. Sem a pretensão de sintetizar a abrangência e profundidade do tema, tomamos como referência, neste artigo, especialmente a perspectiva presente em alguns dos artigos de Basaglia escritos nos primeiros anos da crítica-prática de transformação do manicômio goriziano que, embora constituem um recorte, distante de contemplar a trajetória dessa experiência, apresentam conteúdos significativos que revelam a riqueza e a complexidade da afirmação da liberdade no campo da saúde mental, e, ao mesmo tempo, a necessidade de constante problematização na cotidianidade das práticas dos serviços e projetos substitutivos e territoriais das redes locais.

\section{“A descoberta da liberdade": a crítica-prática de transformação do manicômio goriziano}

Franca Ongaro Basaglia (1981a, 1982a) assinala que os artigos de Basaglia, reunidos nos Scritti I (1981b) e Scritti II (1982b), constituem a história de uma vida, de um pensamento que, de forma contínua, buscou compreender "o que oprime o homem, o que o impede de se expressar, de se relacionar com os outros, de realizar as próprias aspirações" (BASAGLIA, F. O., 1982a, p. viii).

Distinto de um itinerário linear, os escritos expressam diferentes momentos do percurso de Basaglia e se apresentam como "negação e desenvolvimento do [momento] precedente". (BASAGLIA, 1981a, p. xix). Após o primeiro período de aproximação com a cultura psiquiátrica, e com os parâmetros de uma ciência que "apresenta o objeto e os instrumentos da sua análise como dados fixos e indiscutiveis" (BASAGLIA, 1981a, p. xix), Basaglia (1981, p. $\mathrm{xx}$ ) buscou uma compreensão global dos problemas humanos e aprofundou os estudos sobre o pensamento fenomenológico existencial que colocava em cena "o problema do homem, não mais como entidade abstrata definivel segundo um sistema de categorias fechadas, mas como sujeito-objeto de um sofrimento social" $\mathrm{O}$ diálogo com essa perspectiva filosófica, que buscava "restituir ao homem a subjetividade perdida", marcou significativamente sua formação, e, no campo psiquiátrico, contribuiu para encontrar caminhos que possibilitassem aproximar-se da pessoa sem "os anteparos implícitos na rígida definição sintomatológica das sindromes, a partir da compreensão das suas diversas modalidades de existência" (BASAGLIA, 1981a, p. xx). Pirella (1982, p. 6) destaca que nesse percurso verifica-se, também, "o projeto de 'encontro'com o doente orientado para acolher e compreender seu sofrimento e sua subjetividade, com a atitude [..] de 'colocar entre parênteses'os parâmetros objetivantes [..] que encobrem a capacidade de entrar em relação com a experiência vivida [..] do outro". 
No início da década de 1960, o confronto com a violência do manicômio e a condição de destruição das pessoas internadas, que em muito diferia das clínicas universitárias, gerou novos caminhos práticos e teóricos. Basaglia, ao assumir a direção do hospital do psiquiátrico de Gorizia, iniciou um radical processo de crítica e transformação da instituição psiquiátrica, e seus escritos problematizaram a condição da pessoa internada e os significados do manicômio, questionando a psiquiatria, seus instrumentos, e sua finalidade como ciência (BASAGLIA, 1981a).

No primeiro artigo sobre a experiência goriziana, Basaglia (1981b) apresentou e problematizou um conjunto de questões delineando o esboço do que seria a base de seu trabalho (BASAGLIA, F.O., 1982c; COHEN; SARACENO, 2002). Buscando compreender o processo do que se tornou a pessoa internada, enfatizava a liberdade, e assinalava que a transformação da sua condição exigia a elaboração de novas proposições que considerem "o homem no seu livre estar no mundo" (BASAGLIA, 1981b, p. 249).

A prática da equipe goriziana desvelava o manicômio como "lugar [..] de anulação completa de sua individualidade [do doente], como lugar de sua total objetivação" (BASAGLIA, 1981b, p. 250). Embora apresentado como tratamento, o isolamento e o "esquema institucionalizante" no qual se baseia a vida asilar configuram para a pessoa internada: a suspensão dos vínculos com o mundo, a ruptura com qualquer projeto, a impossibilidade de viver a própria vida, impedindo-a "de projetar-se no futuro, inibindo a 'conquista'da própria subjetividade" (BASAGLIA, 1981b, p. 250). Basaglia (1981b, p. 250) destacava que o encontro com a pessoa internada revelou que a partir "do momento em que ultrapassa o muro da internação, o doente entra em uma nova dimensão de vazio emocional".

Com base no conceito de "institutional neurosis" de Burton e nos estudos de Goffman sobre as "instituições totais", Basaglia construiu as noções de "poder institucionalizante" e de "institucionalização", que, para Amarante (1996, p. 89), constituem "o ponto de partida do projeto de desmontagem prático-teórica do manicômio de Gorizia ". Basaglia definiu a institucionalização como:

o complexo de 'danos' derivados de uma longa permanência coagida como aquela no hospital psiquiátrico, quando a instituição baseia-se em princípios de autoritarismo e coerção. Tais princípios, dos quais as regras que o doente deve submeter-se incondicionalmente são expressão, determinam nele uma progressiva perda de interesse que, através de um processo de regressão e de restrição do Eu, o induz a um vazio emocional (BASAGLIA, 1981c, p.259).

A nova proposição pautava-se na afirmação e produção de liberdade uma vez que, para Basaglia, apenas a partir da apropriação da própria liberdade, seria possível, impelir o homem institucionalizado, "destruído pelo poder" da instituição: "à busca de si mesmo, à reconquista da própria individualidade [..] se não se quer que ele continue a identificar o seu vazio interior com o espaço limitado e ameaçador do manicômio" (BASAGLIA, 1981b, p.252).

A temática da liberdade não era estranha à própria história da psiquiatria, e Basaglia (1981b) assinalava que também Pinel invocara a liberdade para os alienados. Entretanto, apontava, citando Foucault, que

'no final do século XVIII [..] não se verifica uma libertação dos loucos, mas a objetivação do conceito da sua liberdade', objetivação que, desde então, levou o doente a identificarse [..] com o esquema da instituição, a institucionalizar-se. Despojado de qualquer elemento pessoal, [..], prisioneiro de seus próprios medos, o doente deveria ser isolado em um mundo fechado onde, mediante a gradual anulação de qualquer possibilidade pessoal, a sua loucura não teria mais força (BASAGLIA, 1981b, p. 252).

Basaglia (1981b, p. 251) enfatizava que "a descoberta da liberdade é a mais óbvia que a psiquiatria poderia fazer [..]; mas, o óbvio é, evidentemente, a matéria mais dificil de enfrentar quando coloca o homem frente a frente consigo mesmo, sem anteparos nem refrações".

Podemos dizer que a afirmação da liberdade, compreendida nessa perspectiva, é fundamental na experiência goriziana, e a busca de caminhos que possibilitassem sua produção na prática engendrou um conjunto de problematizações, delineando as bases das novas relações entre a equipe e as pessoas internadas. Dessa forma, envolvia o conjunto dos atores e requeria que os profissionais tivessem conhecimento de sua liberdade e que pudessem re-conhecer a pessoa internada em sua subjetividade e liberdade. Essa profunda mudança de ótica significava, "a superação de uma relação objetivante com o paciente, na qual [o psiquiatra] não pode ver senão um isolado objeto de estudo [..] em uma relação alienante de servo-senhor (que manteria, sempre, o clima de pseudoliberdade como em Pinel)" (BASAGLIA, 1981b, p.253).

Em um movimento de constante verificação e crítica da realidade, central na perspectiva teórica-metodológica desenvolvida, Basaglia (1981b, p. 256) considerava que o hospital psiquiátrico - "lugar de institucionalização e de alienação induzida" - poderia tornar-se "um outro lugar de alienação, se organizado como um mundo completo em si, no qual todas as necessidades são satisfeitas, como em uma gaiola de ouro", e assinalava que se a relação de força for substituída por uma relação de liberdade doada, vinda do 
exterior, cedida pela figura do "bom profissional", a qual o paciente continua submetido, se observará uma nova forma de institucionalização que, embora distinta, seguirá sendo institucionalização da pessoa internada.

Inicialmente a equipe goriziana organizou o cotidiano do hospital com base nas proposições da comunidade terapêutica de Maxwell Jones. A afirmação da liberdade, a abertura das portas, a ruptura do sistema coercitivopunitivo, a intensidade dos espaços coletivos, a rearticulação dos vínculos com o externo, a potencialização da vida comunitária, a constante crítica da estrutura hierárquicoautoritária, confrontavam a inércia institucional e produziam novas formas de encontro que, a partir das necessidades das pessoas internadas, buscavam construir oportunidades reais, transformar sua condição de institucionalizada, criar possibilidades de seu pertencimento a um coletivo, de ruptura "da serialização institucional, em direção à constituição de um grupo no qual possa definir e afirmar a legitimidade de sua existência" (BASAGLIA, 1981d, p. 407).

Revisitando a experiência goriziana, Franca Basaglia (1997, p.10) destaca que "a liberação da pessoa, o emergir de um sujeito pleno de necessidades [..] foram os primeiros gestos terapêuticos em direção à liberação do internado do manicômio material que o aprisionava e da lógica manicomial que ele mesmo havia incorporado". Distante de um pensamento simplificador, reconhecia-se a complexidade dos significados dessa postura que implica assumir o risco da liberdade; entretanto, como destaca a autora, de uma liberdade sustentada pela capacidade do conjunto do grupo, dos profissionais de "sustentar o conflito que toda pessoa produz [..] e de torná-lo positivo como elemento de reciproca responsabilidade. Responsabilidade que se adquire apenas na possibilidade de crescer, de desenvolverse, e de se confrontar em um clima de liberdade".

Esse complexo processo denominado "luta contra a institucionalização interna” (BASAGLIA, 1981c, p. 266), pautado em relações de reciprocidade, significava que, a partir das possibilidades, conflitos e contradições que emergiam na prática, os lugares das pessoas internadas, dos enfermeiros e dos médicos eram "continuamente colocados em discussão, reconstruídos e novamente destruídos" (BASAGLIA, 1981d, p. 401). Dessa forma, não remetia a um simples "comunitarismo" ou à negação das relações de poder e, antes, tratava-se de um processo gerador de crise todavia, para Basaglia (1981d), era exatamente o "enfrentar e viver as contradições" que possibilitaria construir novas relações, que, de outro modo, tenderiam à cristalização.

Nesse contexto, Franco e Franca Basaglia (1981, p. 309-10) criticaram a "objetivação do homem em sindrome operada pela psiquiatria positivista" e, à luz dos estudos fenomenológicos, afirmaram que era necessário, primeiro, "colocar 'entre parênteses' a doença e o modo pelo qual foi classificada, para poder considerar o doente". A epoché, inscrita na prática, emergiu da necessidade de "poder começar a olhar o doente e o seu modo de agir" (BASAGLIA, 1981e, p. 439) ${ }^{(1)}$. Como assinalam Colucci e Di Vittorio (2001, p. 90), para compreender o significado de "colocar entre parênteses a doença mental", é importante enfatizar que emerge no trabalho de transformação da instituição e na leitura crítica das contradições que o processo de afirmar a liberdade revelou:

"A comunidade terapêutica de Gorizia é a descoberta que o encontro com o doente mental é possivel apenas se ele está 'livre', e se todos os membros [..] estão em um plano de liberdade e responsabilidade".

No cotidiano institucional, "colocar entre parênteses" traduzia-se em intervenções plurais, no intenso trabalho de encarregar-se efetivamente da pessoa internada, de identificar suas necessidades, de aproximar-se de seu sofrimento: iniciava-se a produção de uma diversa e complexa prática terapêutica pautada na compreensão da pessoa, na transformação de suas possibilidades concretas de vida, a partir da construção cotidiana do encontro e da intransigente afirmação da liberdade. A intencionalidade desse projeto não poderia encerrar-se no limite dos muros institucionais e, antes, desde o início, Basaglia e equipe não restringiram a transformação apenas às relações e dinâmicas internas: ao lado das ações de "luta contra a institucionalização interna" era necessário enfrentar a "institucionalização externa" (BASAGLIA, 1981c, p. 264). A articulação entre essas ações expressou a singularidade da experiência goriziana, diferenciando-a da proposição de comunidade terapêutica ${ }^{(2)}$.

Nessa perspectiva, a relação entre profissionais, pessoas

\footnotetext{
(1) Sobre o tema, ver: Amarante, 1996; Barros, 1994; Basaglia, 1981e; Basaglia e Basaglia, F.O., 1981; Colucci e Di Vittorio, 2001; Kinoshita, 2001; Nicácio, 2003.

(2) Em relação à crítica da perspectiva da comunidade terapêutica desenvolvida a partir da experiência goriziana, ver: Amarante, 1996; Barros, 1994; Basaglia, F.O., 1982a; Basaglia, 1985; Colucci e Di Vittorio, 2001; Nicácio, 2003.
} 
internadas e o contexto social assumiu centralidade: era fundamental questionar o modo como a sociedade se relaciona com a loucura, e problematizar a função social do manicômio e da psiquiatria. Essa compreensão do sentido da transformação ampliava a reflexão sobre o papel dos técnicos. Basaglia (1981f) evidenciou o significado do manicômio como expressão da resposta social à experiência da loucura e argumentava que essa relação é a base que conforma o mandato social dos profissionais que operam um equivocado papel de ambigüidade. Dessa forma, é necessário transformar a delegação da sociedade aos profissionais, delegação ao mesmo tempo de tratamento e segregação, de mandato terapêutico e de controle ${ }^{(3)}$. Para Basaglia (1981f, p. 284), "o tratamento do doente mental deveria tender à reconquista de uma liberdade perdida, de uma individualidade subjugada, que é exatamente o oposto daquilo que o conceito de tutela, de defesa, de separação, de segregação significa".

A compreensão do significado do manicômio e do papel dos técnicos, a recusa em legitimar a construção de uma comunidade protegida e artificial, a reapropriação da liberdade e dos direitos pelos internados, o reconhecimento da exclusão social, e sobretudo, as necessidades das pessoas internadas que o processo revelou, indicaram os limites da trajetória e exigiam a construção de novas possibilidades fora do manicômio. Em síntese, as contradições que a própria ação de transformação gerou, colocou em crise a experiência que, naquele período, enfrentava um conjunto de resistências. Franca Basaglia (1992, p.1) assinala que a história do movimento de transformação da instituição psiquiátrica, que construiu as bases que possibilitaram a qualidade inovadora do conteúdo da Lei 180/1978, teve início como história de uma

ilha, de uma utopia de liberdade, [..] no lugar do isolamento, da exclusão [..]. Tratava-se, de fato, de uma ilha, isto é, de um projeto prático e teórico isolado [..]. Isolamento e confronto que não tiveram, todavia, o efeito de reduzir [..] a paixão pelo 'fazer' [..]. Antes, estimularam a concentrar todas as forças [... na criação de laços profundos, intelectuais e afetivos, entre os protagonistas [..] na busca incessante de uma finalidade comum: a utopia prática das liberdades.

Entretanto, para produzir a "utopia prática das liberdades" era necessário partir da experiência da "ilha", não se institucionalizar como realidade separada, nos limites da liberdade concedida, e buscar ativar novas alianças, comunicando-se com as instituições, para viabilizar, de fato, percursos e possibilidades de vida na cidade (BASAGLIA, F.O., 1992).

Basaglia (1985) aprofundou a análise da instituição manicomial no contexto do sistema social, político e econômico: a experiência goriziana tornou-se um laboratório de tomada de consciência coletiva. Na leitura de Colucci e Di Vittorio (2001), a crítica-prática evidenciou o problema da pessoa doente em seu ser excluído e a natureza sociopolítica da instituição psiquiátrica; ao mesmo tempo, "a descoberta da liberdade" constitui "um ponto de não retorno" e exigia enfrentar o problema da vida da pessoa internada e superar o manicômio. Nesse sentido, " $a$ descoberta da liberdade faz irrupção no contexto social, fazendo explodir a contradição psiquiátrica em particular, e o problema da relação entre a produção de verdade e os sistemas de poder em geral" (COLUCCI; DI VITTORIO, 2001, p. 121).

A equipe propôs à administração local o fechamento do manicômio e a abertura de centros de saúde mental na cidade. Frente à recusa, e ciente de que a continuidade do "hospital aberto" justificaria a necessidade do manicômio, confirmando a legitimidade do isolamento, a equipe abriu publicamente o debate, e Basaglia se retirou. A intensidade da crise político-institucional concretizava a complexidade do projeto, e a carta, dirigida às pessoas internadas, sintetizava o processo: "O hospital psiquiátrico de Gorizia deu nesses anos uma indicação prática sobre como enfrentar os problemas do homem doente e de seu sofrimento. [..] uma ação que teve um valor demonstrativo de forma a fazer renascer em muitos a esperança da possibilidade de uma relação diferente entre os homens" (BASAGLIA; BASAGLIA, F. O., 1982, p. 265).

O aprendizado da crítica-prática de transformação do manicômio goriziano foi fundamental para refutar as propostas de simples modernização da instituição asilar. Nos anos que se seguiram, foram desenvolvidas iniciativas em diferentes regiões italianas, e a insígnia "A liberdade é terapêutica? " (MAURI, 1983), ao mesmo tempo afirmação e convite à prática, marca a trajetória triestina iniciada em 1971 por Basaglia e sua equipe.

Cohen e Saraceno (2002, p.19) assinalam a relevância dessa experiência, especialmente de seus valores, para os projetos que visam à produção de sistemas de saúde mental na comunidade, destacando que os serviços triestinos foram construídos com base na "premissa que liberdade é um

(3) Em relação à problematização do papel dos técnicos, ver: Basaglia, 1985; Basaglia e Basaglia, F.O., 1975 ; 1982. 
pré-requisito para o cuidado efetivo". Considerando que na perspectiva basagliana de liberdade, essa não é resultado, e sim base da prática terapêutica, amplia-se para além da crítica do isolamento e da anulação das pessoas internadas, os autores enfatizam que se refere ao "essencialmente humano" e implica o risco da liberdade: "dar à pessoa com transtorno mental grave, a dificil e desafiadora oportunidade de criar uma vida plena de sentido" (COHEN; SARACENO, 2002, p.215).

\section{$O$ aprendizado da experiência do NAPS no contexto do Projeto Santista de Saúde Mental}

A criação do NAPS da Zona Noroeste, em 1989, foi marcada pela aprendizagem coletiva do processo em curso na Casa de Saúde Anchieta sob intervenção da Prefeitura Municipal de Santos: com base na afirmação dos direitos das pessoas internadas e na recusa de legitimação de sua exclusão, diversas ações foram desencadeadas, dentro e fora dos muros institucionais, compondo um complexo processo de desconstrução da "velha ordem" e construção de "nova ordem" pautada na produção de uma "nova ética" (KINOSHITA, 1996a, p. 41).

A afirmação da liberdade, ponto de partida da transformação do "Anchieta" e também da invenção das novas instituições no território, significou, na experiência do NAPS, projeto e contextura: desafio cotidiano de produção de uma cultura de liberdade que gerava múltiplas inovações e conflitos. Como assinala Rotelli (2000, p.4), a transformação das instituições apenas pode ser produzida na prática, em um movimento contínuo que implica a "aceitação do conflito" e a "aceitação do risco" da liberdade "sem o qual a emancipação é impossível".

Certamente, essa proposição requer uma estrutura que não reproduza as formas típicas de controle da lógica asilar, a crítica do isolamento, uma instituição em constante movimento, com livre acesso, capaz de operar "portas abertas" em seus múltiplos sentidos (KINOSHITA, 1996a; NICÁCIO; CAMPOS, 2005). Não obstante a relevância dessas inovações para o cuidar em instituições abertas, o que parece fundamental enfatizar é que o aprendizado da experiência do NAPS revelou que a afirmação da liberdade reafirma e implica novas formas de pensar, cuidar e interagir com as pessoas com a experiência do sofrimento psíquico.

Em primeiro lugar, exigiu transformar os saberes e as práticas pautados na ausência de valor do louco, na sua "condição de objeto de violência", de ser um homem sem direitos e "sem poder contratual" (BASAGLIA, 1985; KINOSHITA, 1996a; 1996b). O exercício de buscar a superação dessa concepção, difusa e enraizada socialmente, e também entre os técnicos, foi uma das principais transformações presentes no dia-a-dia do NAPS e construiu as bases da prática terapêutica.

$\mathrm{Na}$ atenção às situações de crise, especialmente quando envolvia a hospitalidade integral, 24 horas, a afirmação da liberdade parecia revelar, de modo mais evidente, a complexidade de cuidar em liberdade e de validar a experiência das pessoas com sofrimento psíquico (NICÁCIO; CAMPOS, 2004). Entretanto, nessa experiência, a produção de liberdade, compreendida como processo, conquista, participação, construção de possibilidades, atravessou todos os momentos da co-produção de projetos terapêuticos singulares (NICÁCIO, 2003).

A prática cotidiana revelava que propiciar que os usuários se apropriem da própria liberdade requer a transformação dos papéis cristalizados e das respostas pré-formadas, buscar problematizar e contextualizar os significados de liberdade, autonomia, responsabilidade, risco, e produzir estratégias, vínculos, e projetos que possibilitem co-participação, reconhecimento dos saberes e dos recursos dos usuários e dos familiares, fortalecimento de contratualidade, leitura conjunta das situações, ampliação da compreensão das possibilidades de escolha, e potencialização do protagonismo e do poder de decisão. Dessa forma, radicalmente distinta da ação pautada na lógica da tutela asilar, significa, desde os gestos mais elementares presentes no dia-a-dia da prática terapêutica, à complexidade do enfrentamento das situações nas quais as estratégias propostas contrastam com as perspectivas dos usuários e dos familiares, operar a disponibilidade para o encontro, propiciar o exercício de liberdade, promover contextos dialógicos, acompanhar os usuários na vida cotidiana, e mediar interações para validar a experiência das pessoas com sofrimento psíquico.

Essa diversa perspectiva complexifica o campo do cuidado e da interação com os usuários, os familiares, e as pessoas do território: a partir do efetivo reconhecimento do Outro, requer tecer "entrar em relação", aprender a dialetizar as situações, e, em conjunto com os usuários e familiares, criticar as diferentes formas de liberdade abstrata. Trata-se de compreender que a ação de produção de liberdade não significa operar em um campo sem conflitos e antes, implica superar a atitude dilemática e os diversos modos simplistas de manejo de conflitos a partir da anulação de um dos pólos (BASAGLIA, F.O., 1985).

A afirmação e a produção de liberdade não poderiam delimitar-se ao interior do NAPS e das relações no contexto 
institucional. Recordando Basaglia, o risco de fechar-se na instituição, mesmo que aberta e no território, é sempre presente e, na trajetória do NAPS, foram diversos os momentos de confronto com essa questão. Tomando como referência a experiência goriziana, a "utopia prática das liberdades" significa enfrentar as contradições da realidade, e buscar criar possibilidades reais de vida, trilhando, em diferentes dimensões, e com atores diversos, múltiplos "percursos de defesa das liberdades" (BASAGLIA, F.O., 1992, p.3). Com esse conteúdo, reafirma-se a projetualidade dos serviços abertos, substitutivos e territoriais: a prática terapêutica centrada nas pessoas e pautada na coprodução de "projetos de vida" (KINOSHITA, 1996a) necessariamente transborda as fronteiras institucionais, e requer, também, compartilhar, com os usuários, o reconhecimento e a potencialização de relações, de contextos e de recursos - materiais, sociais, culturais - que propiciem construir/ampliar redes de pertencimento e transformar as possibilidades concretas de "estar no mundo".

$\mathrm{O}$ aprendizado da experiência do NAPS indica que a prática concreta de produção de liberdade atravessa o conjunto das relações e dos processos institucionais, envolve todos os participantes, e implica, antes de tudo, a equipe. Como destacam Cohen e Saraceno (2002, p.216), o risco da liberdade é de todos: restituir a liberdade às pessoas com transtornos mentais necessariamente gera transformação nas relações de poder e, dessa forma, inscreve risco também para os trabalhadores, "compelidos a examinar seu papel na instituição". Assim, trata-se, para os profissionais, de, na prática, colocar em discussão seu lugar, e, assumindo o desafiador encargo da responsabilidade, ética e sanitária, na delicada tarefa de aproximar-se e cuidar do sofrimento a partir da afirmação da liberdade, construir, em relação, novas profissionalidades.

Essa proposição exige novos modos de organização da prática cotidiana, isto é, não é possível afirmar a liberdade no cuidado e na projetualidade do serviço se, ao mesmo tempo, não for essa a perspectiva para a equipe e a gestão do serviço. Dessa forma, significa, embora diferente da instituição asilar, a participação de todos no enfrentamento dos diversos modos de hierarquização das relações. Exercício difícil, requer um movimento contínuo de reflexão, e na experiência do NAPS a reunião diária das 12:30 horas constituiu o lugar central de crítica e verificação da realidade. Esse momento cotidiano, o fazer junto, o enfrentamento da inércia institucional, a forte presença dos usuários e dos familiares e, especialmente, a busca de inserção de todos na produção do projeto, foram fundamentais na construção da equipe como coletivo para a sustentação dessa diversa projetualidade da prática. Desafio complexo, e não sem conflitos entre os atores, exatamente porque significa aprender a "viver em um estado de tensão recíproca, no qual - reciprocamente - se considere a necessidade de liberdade do outro" (BASAGLIA; BASAGLIA, F.O., 1981, p. 327).

\section{Considerações finais: a desafiadora tarefa dos CAPS}

O diálogo com as contribuições basaglianas, com autores da desinstitucionalização, e as reflexões sobre a experiência do NAPS consentem compreender que a afirmação da liberdade não pode ser circunscrita aos processos de superação das instituições asilares, e, também, que não é simples de ser produzida nos serviços e projetos territoriais, nos CAPS em particular.

Dessa forma, diferente de simples concordância, exterior ao agir institucional, os serviços substitutivos têm o desafio de traduzir a afirmação da liberdade na prática terapêutica no cotidiano das relações, demonstrando a viabilidade de novas formas de cuidar e interagir com a experiência da loucura e do sofrimento humano. Práticas que necessariamente transcendem espaços institucionais na co-produção de "projetos de vida" nos territórios, propiciando oportunidades reais de enriquecimento para todos, cultivando redes relacionais, tecendo e transformando as possibilidades concretas de vida das pessoas com a experiência do sofrimento psíquico.

Rotelli (1991, p.19), discutindo a perspectiva de "empresa social" na experiência triestina, enfatiza a "liberdade de" e a "liberdade para" como dimensões indissociáveis, movimento contínuo de superação do manicômio, compreendido como desconstrução de saberes, práticas, profissionalidades, e a "liberdade para" a invenção da projetualidade do trabalho no território.

Nesse sentido, e, considerando que os CAPS constituem dispositivos estratégicos na superação do modelo asilar, assume centralidade o lugar que podem ocupar na co-produção de percursos que promovam, sustentem e viabilizem a prática da afirmação da liberdade: construindo as possibilidades de validação das pessoas com a experiência do sofrimento psíquico, compartilhando a criação de novos contextos de trocas sociais, enfrentando, em conjunto, a complexidade dos processos relacionais, institucionais, e sociais para propiciar o efetivo "acesso e exercício de direitos" (ROTELLI, 1999). Na síntese de Rotelli (1987, p. 66):

As instituições da desinstitucionalização são os eixos de sustentação da extensão possível do estado de liberdade. Essa é 
NICÁCIO, F.; CAMPOS, G. W. de S. Afirmação e produção. Rev. Ter. Ocup. Univ. São Paulo, v.18, n. 3, p. 143-151, set./dez. 2007.

a 'liberdade terapêutica'. Outra via não parece viável no interior de um projeto de emancipação concreta. [..] A utopia continua [..], isto é, que existam tantas diferenças e que nenhuma seja excluída: [..] Considero que existem itinerários, mediações materiais, e processos que podem ser praticados [..] para fazer com que essa utopia [..] encontre modos de realizar-se.

NICÁCIO, F., CAMPOS, G. W. de S. The affirmation and production of freedom: a challenge for the psychosocial care centers. Rev. Ter. Ocup. Univ. São Paulo, v.18, n. 3, p. 143-151, set./dez. 2007.

ABSTRACT: The analysis of the panorama of mental health care in the context of the Unified Health System indicates a significant moment in the change process going through the care model. In this scenario it is essential to think hard about the challenges of translating psychiatric reform directives and principals into daily practice of services and substitute projects and, in special, Psychosocial Care Centers - strategic devices of psychosocial care network. Taking as reference Basaglian contributions and deinstitutionalization authors, and the analysis of the trajectory of the Northeastern Psychosocial Care Center as a twenty-four-hour, open, territorial-based, substitutive service, components of the given study, this article discusses the central importance of the role of freedom for overcoming the asylum model. It is noteworthy to say that this perspective reflects innovations in the therapeutic practice, inscribe new signatures for professional practice, and represents new possibilities for the co-production process with people in mental suffering over their life projects in the territories.

KEY WORDS: Mental health. Deinstitutionalization. Mental health services/trends. Community mental health services. Occupational therapy/trends.

\section{REFERÊNCIAS}

AMARANTE, P. D. C. O homem e a serpente: outras histórias para a loucura e a psiquiatria. Rio de Janeiro: FIOCRUZ, 1996. $141 \mathrm{p}$.

BARROS, D.D. Jardins de Abel. Desconstrução do manicômio de Trieste. São Paulo: EDUSP/ Lemos, 1994.

BASAGLIA, F.O. Isole, percorsi delle difese e delle libertà. In: FORUM INTERNAZIONALE PER LA SALUTE MENTALE E LE SCIENZE SOCIALI, 2., Genova, 1992.

BASAGLIA, F.O. Prefazione. In: BASAGLIA, F. (a cura di) Che cos'è la psichiatria? 3a. ed. Milano: Baldini \& Castoldi, 1997. p. 5-14.

BASAGLIA, F. O. Premessa. In: BASAGLIA, F.O. (a cura di). Franco Basaglia. Scritti I (1953-1968). Torino: Einaudi, 1981a. p. ix-x.

BASAGLIA, F.O. (a cura di). Franco Basaglia. Scritti I (1953-1968). Torino: Einaudi, 1981 b.

BASAGLIA, F.O. Premessa. In: BASAGLIA, F.O. (a cura di) Franco Basaglia. Scritti II (1968-1980). Torino: Einaudi, 1982a. p.vii-ix.
BASAGLIA, F.O. (a cura di) Franco Basaglia. Scritti II (1968-1980). Torino: Einaudi, 1982b.

BASAGLIA, F.O. L'itinerario di Franco Basaglia. Sapere, p.10-20, 1982c.

BASAGLIA, F.O. Transformação institucional e objetivos comuns. In: BASAGLIA, F. (org.) A instituição negada. Rio de Janeiro: Graal, 1985. p. 273-283.

BASAGLIA, F. Introduzione generale ed esposizione riassuntiva. In: BASAGLIA, F.O. (a cura di). Franco Basaglia. Scritti I (1953-1968). Torino: Einaudi, 1981a. p.xix-xliv.

BASAGLIA, F. La distruzione dell'ospedale psichiatrico come luogo di istituzionalizzazione. In: BASAGLIA, F.O. (a cura di). Franco Basaglia. Scritti I(1953-1968).Torino: Einaudi, 1981 b. p. 249-58.

BASAGLIA, F. La "comunità terapeutica" come base di um servizio psichiatrico. In: BASAGLIA, F. O. (a cura di). Franco Basaglia. Scritti I (1953-1968). Torino: Einaudi, 1981c. p. 259-82.

BASAGLIA, F. La libertà comunitaria come alternativa alla regressione istituzionale. In: BASAGLIA, F. O. (a cura di). 
Franco Basaglia. Scritti I (1953-1968). Torino: Einaudi, 1981d. p. 394-409.

BASAGLIA, F. Corpo e istituzione. In: BASAGLIA, F.O. (a cura di). Franco Basaglia. Scritti I (1953-1968). Torino: Einaudi, 1981e. p. 428-41.

BASAGLIA, F. Potere ed istituzionalizzazione. In: BASAGLIA, F.O. (a cura di). Franco Basaglia. Scritti I (1953-1968). Torino: Einaudi, 1981f. p. 283-93.

BASAGLIA, F. (org.). A instituição negada. Rio de Janeiro: Graal, 1985.

BASAGLIA, F.; BASAGLIA, F.O. Un problema di psichiatria istituzionale. In: BASAGLIA, F.O. (a cura di). Franco Basaglia. Scritti I (1953-1968). Torino: Einaudi, 1981. p. 309-28.

BASAGLiA, F.; BASAGLIA, F.O. Crimini di pace. In: BASAGLIA, F.O. (a cura di). Franco Basaglia. Scritti II (1968-1980). Torino: Einaudi, 1982, p. 237-338.

BASAGLIA, F.; BASAGLIA, F.O. (a cura di). Crimini di pace. 2. ed. Torino: Einaudi, 1975.

BRASIL. MINISTÉRIO DA SAÚDE. Caderno Informativo do Congresso Brasileiro de CAPS. Saúde mental: cuidar em liberdade e promover a cidadania. Brasília, 2004.

BRASIL. MINISTÉRIO DA SAÚDE. Conselho Nacional de Saúde. In: Conferência Nacional de Saúde Mental, 3., Brasília, 2001.

BRASIL. MINISTÉRIO DA SAÚDE. Saúde mental no SUS. Brasília, 2007.

COHEN, A.; SARACENO, B. The risk of freedom: mental health services in Trieste. In: COHEN, A.; KLEINMAN, A.; SARACENO, B. (ed.). World mental health casebook: social and mental health programs in low-income countries. New York: Plenum Publishers, 2002. p.191-221.

COLUCCI, M; DI VITTORIO, P. Franco Basaglia. Milano: Bruno Mondadori, 2001.

FÓRUM MINEIRO DE SAÚDE MENTAL (FMSM). Samba na cabeça. Belo Horizonte: FMSM. Associação dos Usuários dos Serviços de Saúde Mental de Minas Gerais. CD-Rom.
KINOSHITA, R.T. Entrevista para TV Tam-Tam. Santos: 1989.

KINOSHITA, R.T. Em busca da cidadania. In: CAMPOS, F. C. B.; HENRIQUES, C. M. P. (org.). Contra a maré, à beira mar: a experiência do SUS em Santos. São Paulo: Scritta, 1996a. p. 39-49.

KINOSHITA, R.T. Contratualidade e reabilitação psicossocial. In: PITTA, A (org.). Reabilitação psicossocial no Brasil. São Paulo: Hucitec, 1996b. p. 55-9.

KINOSHITA, R.T. O Outro da Reforma. Campinas, 2001. 250f. Tese (Doutorado) - Universidade Estadual de Campinas, Campinas, 2001.

MAURI, D. (a cura di) La libertà è terapeutica? Milano: Feltrinellli, 1983.

NICÁCIO, F. Utopia da realidade. 2003. Campinas, 2003. $224 \mathrm{f}$. Tese (Doutorado). Universidade Estadual de Campinas.

NICÁCIO, F.; CAMPOS, G.W.S. A complexidade da atenção às situações de crise. Rev. Ter. Ocup. Univ. São Paulo, v. 15, n. 2, p. 71-81. 2004.

NICÁCIO, F.; CAMPOS, G.W.S. Instituições de "portas abertas". Rev. Ter. Ocup. Univ. São Paulo, v. 16, n. 1, p. 40-6. 2005.

PIRELLA, A. Il giovane Basaglia e la critica della scienza. Sapere, p. 4-9. 1982.

ROTELLI, F. Le istituzione della deistituzionalizzazione. In: GIANNICHEDDA, M.G.; BASAGLIA, F.O. (a cura di) Psichiatria, tossicodipendenze, perizia. Milano: Franco Angelli, 1987. p. 55-68.

ROTELLI, F. Lo scambio sociale. In: GALLIO, G. (a cura di). Nell impresa sociale. Trieste: Edizione E, 1991. p. 19-39.

ROTELLI, F. Opening address to the WAPR Congress. In: WORLD CONGRESS WAPR: Psychosocial rehabilitation. Paris, 2000. 5 p. Disponível em: http://www.exclusion.net.

ROTELLI, F. Riabilitare la riabilitazione. In: ROTELLI, F. Per la normalità. Taccuino di uno psichiatra negli anni della grande riforma. 2a ed. Trieste: Asterios, 1999. p. 104-113. 